\title{
The Presence of a Mobile Phone Does Not (Necessarily) Change the Fundamental Processes of Face-to-Face Relational Conflict
}

\author{
David J. Roaché ${ }^{1}$, John P. Caughlin², Ningxin Wang ${ }^{3}$, and Kimberly P. Pusateri ${ }^{4}$ \\ ${ }^{1}$ Christopher Newport University, ${ }^{2}$ University of Illinois at Urbana-Champaign, \\ ${ }^{3}$ National University of Singapore, ${ }^{4}$ Northwestern University
}

There is a long history of scholarship on how communication contributes to satisfying conversations and relationships (e.g., Fincham, Rogge, \& Beach, 2018; Hecht, 1978; Roberts, 2000). Even as the role of communication in satisfying relationships has endured, communication technologies have become integral to most contemporary close relationships (Parks, 2017). According to a Pew Research Center (2019) report, $96 \%$ of adults in the United States own a cell phone and $81 \%$ of adults own a smartphone.

The use of new technologies in relational communication has become so prevalent that some scholars (e.g., Sbarra, Briskin, \& Slatcher, 2019) and popular authors (e.g., Passy, 2019) have suggested that how people use mobile technologies is transforming and potentially interfering with fundamental relational communication processes. Certainly, people attending to smartphones can be disruptive; about half of adults in committed, cohabiting, or married relationships report that their partner is distracted by their smartphone during conversations (Vogels \& Anderson, 2020). Turkle (2008) argues that the expectation for responding to others via mobile phones has become so prevalent that people experience being "always-on/always-on-you" (p. 122), which she contends can interfere with attention to face-to-face interactions. The potential distraction from mobile phones is salient enough that some studies have suggested that even the "mere presence" of a smartphone can disrupt productive communication and potentially undermine relational quality (e.g., Misra, Cheng, Genevie, \& Yuan, 2016; Przybylski \& Weinstein, 2013).

Given the prevalence of claims concerning the deleterious effects of using mobile technologies on relational processes, it is important for scholars to examine such claims. Yet, given that recent theorizing on technology and relationships has emphasized how people in close relationships incorporate multiple media into their relational communication (e.g., High, 2019; Parks, 2017; Taylor \& Bazarova, 2018), it is important not to consider the presence of mobile devices in isolation of larger relational communication processes. The communication interdependence perspective (e.g., Caughlin \& Sharabi, 2013; Pusateri, Roaché, \& Wang, 2015), for instance, begins with the assumption that relationships exist in "several media at once" (Walther \& Parks, 2002, p. 531). The emphasis on relational communication

CONTACT David Roaché david.roache@cnu.edu Department of Communication, Christopher Newport Univesity, 1 Avenue of the Arts, Newport News, VA 23606, USA 
occurring across multiple modes highlights the need to study face-to-face communication processes along with technologies to understand contemporary close relationships.

Most work on communication interdependence to date has focused on how modes of communication are related to each other, even when are not used simultaneously; for example, difficulty transitioning between face-to-face communication and mediated communication is inversely related to relational closeness and satisfaction (Caughlin \& Sharabi, 2013; Pusateri et al., 2015; Wang, Roaché, \& Pusateri, 2019). Yet, the communication interdependence perspective also suggests that it is important to examine the presence of mobile technologies while relational partners are simultaneously engaging in face-to-face communication. As Sharabi and Dorrance Hall (2020), recently noted, the communication interdependence perspective is aimed at understanding the ways that "technologies are interwoven with face-to-face relationships" (p. 1). Even an idle device is an interdependent component of in-person conversations given that the presence of mobile phones may "crowd out face-to-face interactions" (Przybylski \& Weinstein, 2013, p. 244). Certainly, partners using their mobile devices during face-to-face encounters is another example of how technologies are integrated into interactions (e.g., using a phone to help distract from a topic one wishes to avoid discussing).

The current study examines both the presence of mobile devices and faceto-face processes within relational conflicts, a context with potentially important relational implications. Exploratory data from college students, for example, indicate that college students reported that the presence of mobile phones and other communication technology during face-to-face conflict conversations with their romantic partners made such interactions more challenging (Caughlin, Basinger, \& Sharabi, 2017). Thus, there is reason to probe further what impact, if any, the presence of mobile phones has on face-to-face conflict interactions.

The current study is distinct from nearly all previous scholarship on communication technologies and relationships because it examines both mobile technologies and the nature of the face-to-face communication processes within the same study. To our knowledge, this is the first study examining the potential effects of the presence of mobile phones that also directly examines the nature of the interaction between relational partners. Doing so is essential because it can provide direct evidence regarding questions about whether mobile technologies are fundamentally interfering with relational communication processes, such as conflict interactions. Suggestions that mobile phones interfere with relational communication (e.g., Passy, 2019; Sbarra et al., 2019) could potentially call into question much of what is known about the association between communication and relational well-being. In contrast, the communication interdependence perspective suggests that mobile technologies simply have become another means by which partners enact their relationships (Caughlin \& Sharabi, 2013). Accordingly, the basic conflict processes should endure and operate similarly irrespectively of the presence of mobile technologies. Yet the possibility that conflict processes may be different when people have access to their mobile phones is something that must be examined empirically. 


\section{The Presence of Technology in Relational Communication}

The presence of technology certainly can adversely impact face-to-face interaction (for review, see Caplan, 2018). Some people in families and relationships report a more generalized "technoference" from mobile technologies, referring to the frequent intrusions that technologies have during our interactions - and the constant possibility of further interruptions so long as the technology is present (McDaniel \& Coyne, 2016). The presence of mobile devices in face-to-face interactions may invite partner phubbing, which occurs when a partner's phone use interrupts a conversation (Roberts \& David, 2016). Among college student dyads, partner phubbing is associated with less conversational intimacy (Vanden Abeele, Hendrickson, Pollman, \& Ling, 2019). Clearly, technological intrusions through the use or mere presence of mobile devices have at least the potential to diminish conversation quality.

The notion of technoference suggests that just the presence of mobile technologies may generally interfere with relational processes. Indeed, some studies suggest that the mere presence of technology (i.e., even without active use) diminishes conversational enjoyment and relational quality. For instance, one such study showed that the presence of a mobile phone that did not belong to either person in zero-history dyads was associated with decreased levels of empathic concern, closeness, and relationship quality (Przybylski \& Weinstein, 2013). Other studies have shown that when a mobile phone is present, individuals feel less connected to their interaction partner (Misra et al., 2016) and are more distracted (Thornton, Faires, Robbins, \& Rollins, 2014). Additionally, Misra et al. (2016) found that not only was empathic concern lower in the presence of a smartphone, this effect was heightened by the closeness of the preexisting relationship between dyad members.

Although such research suggests that smartphone presence may substantially alter the dynamics of face-to-face interactions, more recent evidence is less supportive of this possibility. Two studies (Allred \& Crowley, 2017; Crowley et al., 2018) using designs similar to the Przybylski and Weinstein (2013) study failed to reproduce the effect that the presence of technology alone diminishes conversation quality. The Allred and Crowley (2017) study did find that mobile phone presence had an adverse effect on conversation quality when participants recalled the device being present, but there was no general effect of phones being present. Crowley et al. (2018) found no evidence for such an effect. A lack of consensus with respect to the presence of a mobile phone in interpersonal interactions is noteworthy, and of course, mixed evidence is grounds for further investigation.

One reasonable way to proceed is to examine the presence of mobile phones in a context that is particularly likely to show effects if there are any. We nominate relational conflict as such a context. Successful conflict management involves complex cognitive processes and the need for behavioral control (Canary \& Sillars, 2013; Roloff \& Wright, 2013), and there is evidence that the presence of a mobile device can interfere with the complex cognitive processes. Simply having one's smartphone nearby impacts individuals' abilities to perform certain cognitive tasks, making it harder for people to pay attention to the task at hand, which is a phenomenon labeled "smartphone induced brain drain" (Ward, Duke, Gneezy, \& Bos, 2017, p. 140). Even if individuals can handle a routine daily interaction when 
somewhat distracted by technology, the distraction would be more problematic when thoughtful attention is required. Moreover, there is some evidence that the most likely conditions for observing an impact of the presence of communication technology are those involving complex tasks or conversation topics; for example, Przybylski and Weinstein (2013) found that the effects of a smartphone on conversation quality were more salient during meaningful conversations rather than casual ones. Thornton et al. (2014) also found that the presence of a smartphone affected scores on complex cognitive tests but not simple ones. In short, because productive conflict management requires attention to a complex situation, conflict interactions are well suited for examining the first hypothesis:

H1: The presence of technology will negatively influence the quality of conflict interactions (as indexed by conversation satisfaction, perceived resolvability, and perceived communication effectiveness).

\section{Sex Differences and Technology Presence}

Another potential reason for mixed results with respect to the presence of mobile technologies is the fact that previous work generally has not taken into account how individuals may differ with respect to how they react to technologies, which can obscure potential effects. Gender is a potentially important factor. On average, men and women have different attitudes regarding the use of mobile devices. Women are more likely than men to state that mobile phones harm interpersonal interaction (Rainie, 2015), and women report being more irritated by their partner's mobile phone use than men do (Vogels \& Anderson, 2020). Similarly, Forgays, Hyman, and Schreiber (2014) found that across various social contexts, men were more likely than women to report that it is appropriate to take mobile calls and to text, even in intimate encounters like a date.

Such findings suggest that men are generally more tolerant than women regarding intrusions of mobile devices into in-person interpersonal interactions, but it is unclear precisely how differing attitudes about appropriateness might shape the connection between the presence of phones and evaluations of relational communication. Indeed, there is some indirect evidence that despite their overall views on mobile phones during interactions, women may have positive evaluations associated with some mobile phone usage. In a study of married couples, Davies et al. (2012) found that the extent to which husbands used their phones for self-reactive reasons (e.g., using media to relieve boredom, feeling less lonely) was positively related to wives' satisfaction, whereas the wives using their phones for self-reactive reasons was associated with less satisfaction with their husbands. Noting the relational context is important because romantic couples may develop norms around phone use (Miller-Ott \& Kelly, 2016), which implies that overall gender differences in the population (e.g., Rainie, 2015) may not be applicable to differences in dating relationships. Although previous studies did not find gender differences with respect to the effects of presence (e.g., Misra et al., 2016; Przybylski \& Weinstein, 2013), this would not necessarily extend to conflict interactions among dating partners. In sum, there is evidence that men and women in hetero- 
sexual romantic relationships may view mobile phone usage differently in ways that shape their satisfaction with conversations and relationships. Because women are in general less tolerant about technology use during face-to-face conversations, there is reason to believe that having a smartphone present while managing conflict may impact women more significantly. However, because the exact association is unclear, we pose the following question:

RQ1: Will biological sex moderate the effect of the presence of technology on the quality of conflict interactions (as indexed by conversation satisfaction, perceived resolvability, and perceived communication effectiveness)?

\section{Communication Behaviors during Relational Conflict}

There is a robust literature showing that how individuals manage conflict "prior to, during, and after a conflict" (Roloff \& Chiles, 2011, p. 430) is critical for relationship functioning and well-being. Obviously, there are myriad behaviors that people can enact during conflict, but a number of studies and conceptual schemas emphasize a crucial distinction between engaging a conflict using positive versus negative strategies or affect (e.g., Caughlin, Vangelisti, \& Mikucki-Enyart, 2013; Sillars \& Canary, 2013).

The distinction based on the valence of conflict engagement has various labels, such as integrative versus distributive strategies (Bevan, Cummings, Engert, \& Sparks, 2017; Sillars, 1986), face honoring versus face threatening strategies (Sillars \& Canary, 2013), and positivity versus negativity (Caughlin et al., 2013). Although there are important distinctions in the labels and within the general categories (e.g., Sillars, 1986), the broad distinction between positivity and negativity during conflict is widely recognized as meaningful for understanding the outcomes of conflicts and the implications of conflict for relationships. Negativity during conflict typically is associated with poor resolution, sustained or increasing hostility between partners, and poor individual and relational outcomes (Roloff \& Wright, 2013). Although the evidence for the benefits of positive strategies during conflict is less consistent than the evidence for the harmful impact of negative strategies (Roloff \& Chiles, 2011), learning to manage conflict with constructive positivity can help couples foster satisfying relationships (Cupach, 2015; Whitton, James-Kangal, Rhoades, \& Markman, 2018). In addition, the ability to verbally and nonverbally communicate during conflict is essential for rewarding and satisfying close relationships (Caughlin et al., 2013; Cupach, 2015). Although it is possible that the presence of technology could disrupt the well-established associations between conflict behaviors and outcomes, the long history of findings pointing to the importance of these behavioral dimensions led us to pose:

H2: Positivity will be positively, and negativity will be negatively, related to the quality of conflict interactions (as indexed by conversation satisfaction, perceived resolvability, and perceived communication effectiveness). 


\section{Face-to-Face Relational Conflict and the Presence of Mobile Phones}

Finally, it is important to consider conflict behaviors and technologies together. If the presence of technology significantly alters the dynamics of how conflict usually functions, it could affect how conflict behaviors are related to outcomes. According to the communication interdependence perspective, communication modes may interfere with or facilitate relational communication (Pusateri et al., 2015). College students' accounts of their own relational conflict suggest that mobile phones and other communication technologies during FtF conflicts can make some conversations more challenging (Caughlin et al., 2017). Some individuals, for instance, reported that the presence of technology during conflict created opportunities for their partner to distance themselves from the conversation, such as being distracted by or staring at their device.

From a communication interdependence perspective, it is important to not only examine the potential effects of such distractions and interruptions but also consider how the behaviors involved in attending to or oriented toward a communication technology might shape the meaning or impact of other behaviors in the system. The potential to be distracted by one's devices, for instance, could shape how one views their partner's conflict behaviors. A person distracted by a phone may not fully notice or appreciate attempts to constructively resolve issues, which could reduce or eliminate any benefits of otherwise constructive behaviors. Thus, mobile phones could alter established findings pertaining to communication behaviors during conflict, which would have major implications for our understanding of communication and conflict. On the other hand, if there is evidence that the usual associations between conflict behaviors and outcomes hold regardless of whether a phone is present, it would suggest that the primary factor impacting the quality of conflict interactions is the communication behaviors between partners, even as technology has become more frequently implicated in relational encounters. In short, it is important to test the interaction between the presence of communication technology and communication behaviors during the conflict episode:

RQ2: Will the presence of technology moderate the associations of positivity and negativity with the quality of conflict interactions (as indexed by conversation satisfaction, perceived resolvability, and perceived communication effectiveness)?

\section{Method}

\section{Participants}

Undergraduate students from a large public Midwestern university who were at least 18 years of age and currently in a romantic relationship were invited to participate in this study in exchange for a chance to win a $\$ 75$ Amazon eGift card. The sample included 58 heterosexual dating couples ( $N=116$ individuals). Participants were approximately 21 years old $(M=20.53, S D=1.96$; range $18-29$ years old), and they self-reported as either European American (39.80\%), Asian or Asian American (31.40\%), African American (15.30\%), Latino/a (11.00\%) or other 
(2.50\%). The dating couples had been in a romantic relationship for approximately 15 months ( $M=14.78$ months; $S D=12.21$ months; range: 1 to 60 months).

\section{Procedure}

Participating couples had two 10-minute video recorded interactions about two different current topics of conflict in their romantic relationship. After completing informed consent procedures, participants completed a short questionnaire about their relationship. Next, they nominated two serial argument topics with the following written instructions: "Please think of two topics/issues about which (1) you and your current partner had multiple arguments, and (2) it is likely you and your partner will argue about these topics in the future." A serial argument is an ideal type of conflict for this investigation because these are repeated topics of disagreement (Johnson \& Roloff, 1998), and they are likely to occur again outside of the laboratory setting. The first topic identified by each dyad member was chosen for discussion, and the order of discussion was determined by a coin toss. If both members identified the same first topic, then that topic was discussed first, and the second topic for discussion was selected from the participant whose topic had been assigned to be discussed second based on the results of the coin toss. After each interaction, participants completed a short questionnaire about each serial argument conversation.

Dyads were randomly placed into one of three conditions. In the control condition (i.e., the "technology free" condition; $n=17$ dyads), dyads were instructed to leave their communication devices in the laboratory waiting room. There were two conditions involving technology, and in both cases, participants were instructed to be in possession of their smartphones or other technologies during the interactions. Whereas some studies use a smartphone that does not belong to participants (Przybylski \& Weinstein, 2013), we explicitly asked participants to bring their own devices into the interaction space to ensure that they would be aware of the technology. Given the evidence that such awareness may be key to any effects of the presence of technology (Allred \& Crowley, 2017), making all participants aware of the technology should maximize the potential for the presence of the technology to have effects.

The first condition with technology was the "technology on" condition, and dyads were instructed to bring their belongings into the research laboratory. Participants ( $n=22$ dyads) in this condition were given the instructions that they could use their technologies during the interaction, and they should keep their devices on and at a normal volume, if that is what they would normally do when having a conflict interaction. The third condition was the "technology in hands" condition. Participants ( $n=19$ dyads) received the same instructions as the "technology on" condition, with the additional instructions that they should keep their devices in their hands during the interactions. Although the broad term "technology" was used throughout the instructions to participants and a few participants had their laptops out, the only technology participants held in their hands for the study were smartphones; thus, we frequently refer to the technology as smartphones throughout this manuscript. 


\section{Measures}

Conversation satisfaction. Immediately following each interaction, participants reported their level of conversation satisfaction (adapted from Scott and Caughlin, 2014). Participants reported their agreement with five statements (e.g., "the conversation went well") on a seven-point Likert scale $(1=$ strongly disagree, $7=$ strongly agree). The measure achieved good internal consistency $(\alpha=.88)$. Male participants $(M=5.08, S D=1.38)$ reported marginally higher conversation satisfaction than their female partners $(M=4.98, S D=1.46)$.

Perceived resolvability. After each interaction, participants responded to Johnson and Roloff's (1998) perceived resolvability scale with a seven-point Likert scale $(1=$ not at all, 7 = to a great extent). The four-item scale measured the extent to which participants believed the serial argument will be reconciled in the future (e.g., "I believe that it will be resolved in the future"). The measure reached acceptable internal consistency $(\alpha=.73)$. Males $(M=4.24, S D=1.21)$ reported greater confidence the arguments would be resolved than did their female partners $(M=4.17$, $S D=1.20)$.

Conversation effectiveness. Participants also responded to the extent to which each conversation was effective toward resolving or improving the serial argument topic. Four items assessed conversation effectiveness: "How much of a difference did the conversation you just had make towards resolving your conflict?"; "How much better did the conversation you just had make the conflict?"; "How helpful was this conversation in solving your conflict?"; and "To what extent did you resolve the issue during this conversation?" The four-item measure utilized a 5-point Likert scale with higher scores reflecting greater perceived effectiveness and was internally consistent $(\alpha=.95)$. Male participants $(M=2.84, S D=0.95)$ reported slightly greater effectiveness scores compared to their female partners $(M$ $=2.66, S D=1.03$ )

\section{Communication Behavior Ratings}

Six trained graduate student raters who were blind to the purpose of the study completed ratings on the audio for each participant's verbal communication during the two serial argument conversations. Although video recordings were available, we used audio alone to prevent the raters from discerning that there were different conditions involving mobile devices. The codebook was adapted from existing research on conflict interactions (Papp, Kouros, \& Cummings, 2009; Sillars, 1986). The raters were instructed to consider both frequency and intensity of behaviors when assigning values, and they had an opportunity to discuss and come to consensus about the meaning of the dimensions, but all coding was done independently. The raters evaluated participants' negativity using assessments of the amount of (a) blame (i.e., blaming, accusing, or criticizing the partner), (b) pressure for change (i.e., demanding, nagging, or pressing for change in partner), and (c) defensiveness (i.e., avoiding blame or responsibility by using justifications, excuses, defending his/her own position, interrupting rather than listening, or protecting his/her own point of view). Coders also evaluated participants' positive communication behaviors by rating the (a) amount of conciliation (i.e., expressing supportiveness and a willingness to reconcile disagreements) and (b) positive 
affect toward partner (i.e., expressing care, concern or appreciation toward his/ her partner). The ratings were completed using a seven-point scale $(1=$ very little, $7=$ very much) with one item measuring each dimension. Additionally, the raters assessed avoidance, withdrawal, expressing critical feelings, and analytical discussion, but these dimensions were discarded due to low incidence, variation, and reliability.

Composite measures for positive and negative communication behaviors were computed in two steps. First, intercoder reliability was established by calculating the intraclass correlation coefficient (ICC) estimates with 95\% confidence intervals based on a 2-way mixed effects model for consistency (Shrout \& Fleiss, 1979). Intraclass correlation coefficients were acceptable for blame, $\operatorname{ICC}(3,6)=.90$, pressure for change, $\operatorname{ICC}(3,6)=.79$, and defensiveness, $\operatorname{ICC}(3,6)=.81$. The intraclass correlation coefficients were moderately reliable for conciliation, $\operatorname{ICC}(3,6)=.65$, and positive affect toward partner, $\operatorname{ICC}(3,6)=.64$, respectively. The relatively low reliability estimates may be a product of low variability in the ratings (e.g., Koo \& $\mathrm{Li}, 2016)$. Second, reliability analysis was performed on the data. The three-item index for negative communication behaviors achieved good reliability $(\alpha=.87)$, and the two-item index for positive communication behaviors achieved moderate reliability $(\alpha=.61)$. The indices were summed and averaged for positive communication and negative communication behaviors (see Table 2 for descriptive statistics by biological sex).

\section{Results}

\section{Preliminary Analyses}

Three sets of preliminary tests were performed on the data. First, because there were no significant differences between the two technology conditions on any of the key variables, we collapsed the two technology conditions to increase statistical power to detect the impact of having smartphones present. Second, correlation analyses for females, males, and within dyads were conducted. Results showed that 7 of the 10 correlations were significant for males, and all 10 correlation coefficients were significant for females. Within dyad correlations were positive and significant for all variables except for perceived resolvability (see Table 1). Third, the data were evaluated for differences by biological sex. There were no significant differences between males and females on the self-report data. However, raters scored females' communication as significantly less positive and more negative than males' communication (see Table 2).

\section{Main Analyses}

Multilevel modeling with two level models was performed on the data using the linear and nonlinear mixed-effects model (nlme) package in R (Pinheiro, Bates, Deboy, Sarkar, \& R Development Core Team, 2018) with maximum likelihood (ML) estimation. Following Kenny, Kashy, and Cook's (2006) recommendations, these data were analyzed at two levels because both conversation (i.e., time) and person are nested within dyads. All continuous predictor variables were grand- 


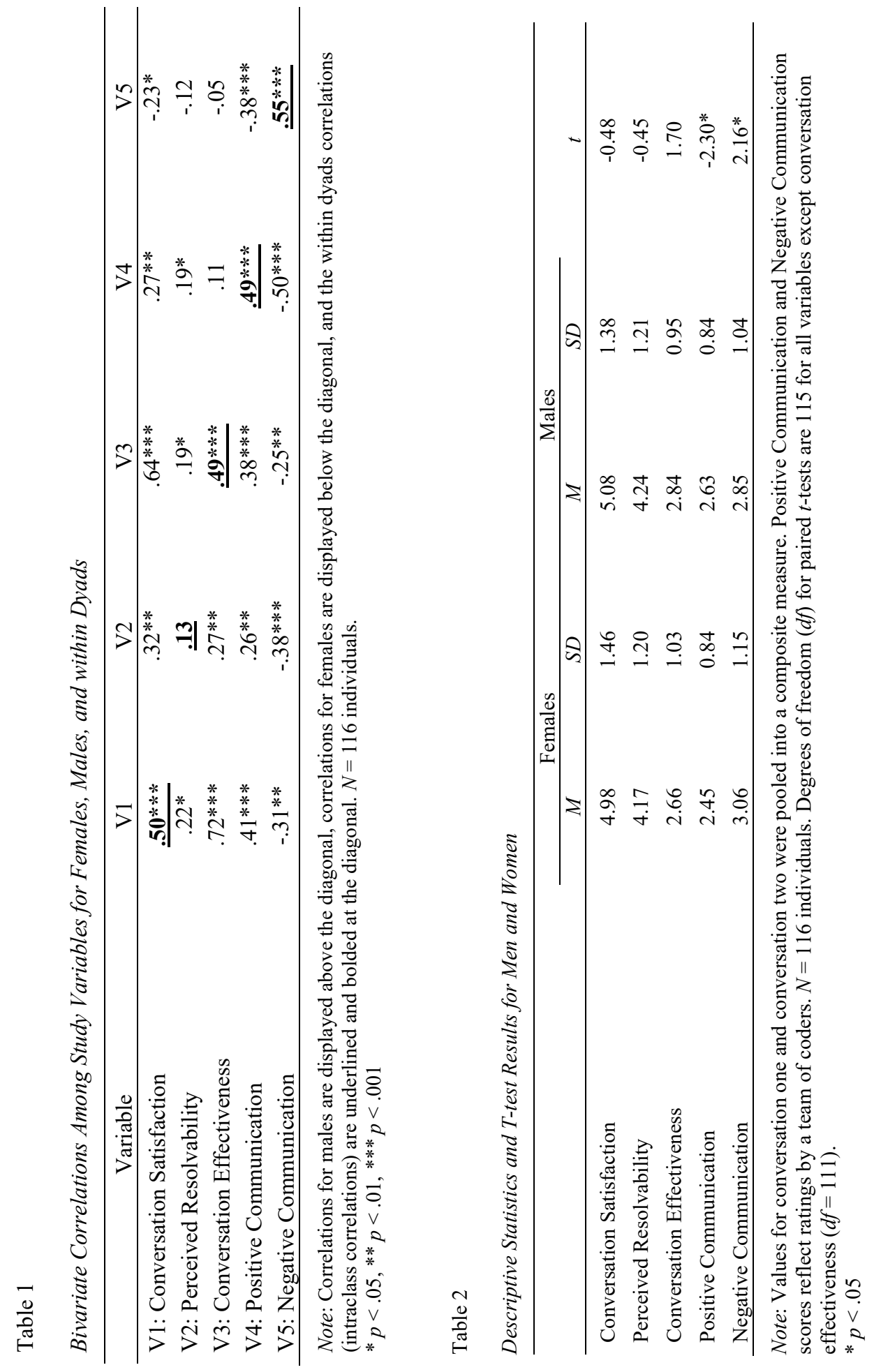


mean centered to minimize collinearity issues (Aiken \& West, 1991; Kreft \& de Leeuw, 1998), to account for the predictor variables not having a true zero point (Field, Miles, \& Field, 2012), and to demonstrate the effect size for a fixed effect in multilevel models (Lorah, 2018). Nakagawa and Schielzeth's (2013) marginal coefficient of determination $\left(R^{2}\right)$ statistic with $95 \%$ confidence intervals was calculated to show the amount of variance explained by the fixed effects in the models. The marginal $R^{2}$ statistic is a single goodness-of-fit measure for all fixed effects in a multilevel model (Lahuis, Hartman, Hakoyama, \& Clark, 2014).

Four variables were entered as level-1 covariates in the multilevel models: age, biological sex, conversation number (i.e., first or second serial argument conversation), and relationship satisfaction. Controlling for relationship satisfaction accounts for sentiment override, which happens when individuals' general assessments of their relationships influence their assessments of specific interactions (e.g., Waldinger \& Schulz, 2006). All categorical predictor variables (e.g., biological sex, experimental condition, conversation) were entered as effect-coded variables. Power was calculated using the $t$-method (Muryama, Usami, \& Sakaki, 2020) to determine what a future study with a sample of this size ( $n=58$ dyads) would be to detect moderate and large effects, respectively. Results showed that power to detect a moderate effect $(r=.3$, as defined by Cohen, 1992) was .63, and the power to detect a large effect $(r=.5)$ was .98 .

Smartphone presence and conversation quality. The first hypothesis predicted that the presence of technology would negatively influence the quality of conflict interactions. A trio of identical multilevel models were evaluated to assess the impact of technology presence on conversation quality (see Table 3). The presence of technology during the interactions was not significantly associated with conversation satisfaction $\left(b=-0.07, p=0.65, R^{2}=.002,95 \% \mathrm{CI}[>.00, .03]\right)$, perceived resolvability $\left(b=-0.04, p=0.74, R^{2}=.001,95 \% \mathrm{CI}[>.00, .03]\right)$, or conversation effectiveness $\left(b=-0.02, p=.84, R^{2}=.002,95 \%\right.$ CI $\left.[>.00, .03]\right)$.

Smartphone presence, biological sex, and conversation quality. The first research question concerned whether biological sex would moderate the impact of the presence of technology on conversation quality. A second trio of multilevel models were evaluated to assess whether biological sex interacted with the presence of technology on conversation quality (see Table 4). Results showed that biological sex significantly moderated the impact of technology presence on conversation satisfaction $\left(b=0.19, p=0.039, R^{2}=.02,95 \%\right.$ CI [>.00, .07]) and conversation effectiveness $\left(b=0.16, p=.007, R^{2}=.03,95 \%\right.$ CI [>.00, .08]), but not perceived resolvability $\left(b=0.03, p=.73, R^{2}=.00,95 \% \mathrm{CI}[>.00, .03]\right)$.

The significant interaction between biological sex and technology presence on conversation satisfaction was evaluated by estimating simple slopes (Preacher, Curran, \& Bauer, 2004). Further probing of the simple slopes for significant cross-level interaction effects showed no significant interaction effects. However, the presence of technology had a negative slope for females, $b=-0.26, t(152)=-1.53$, $p=.13$, and a positive slope for males, $b=0.11, t(152)=0.70, p=.48$ (see Figure 1).

Likewise, the simple slopes for the interaction between biological sex and technology presence on conversation effectiveness were evaluated (see Figure 2). The cross-level interaction effect revealed that the presence of technology had a 


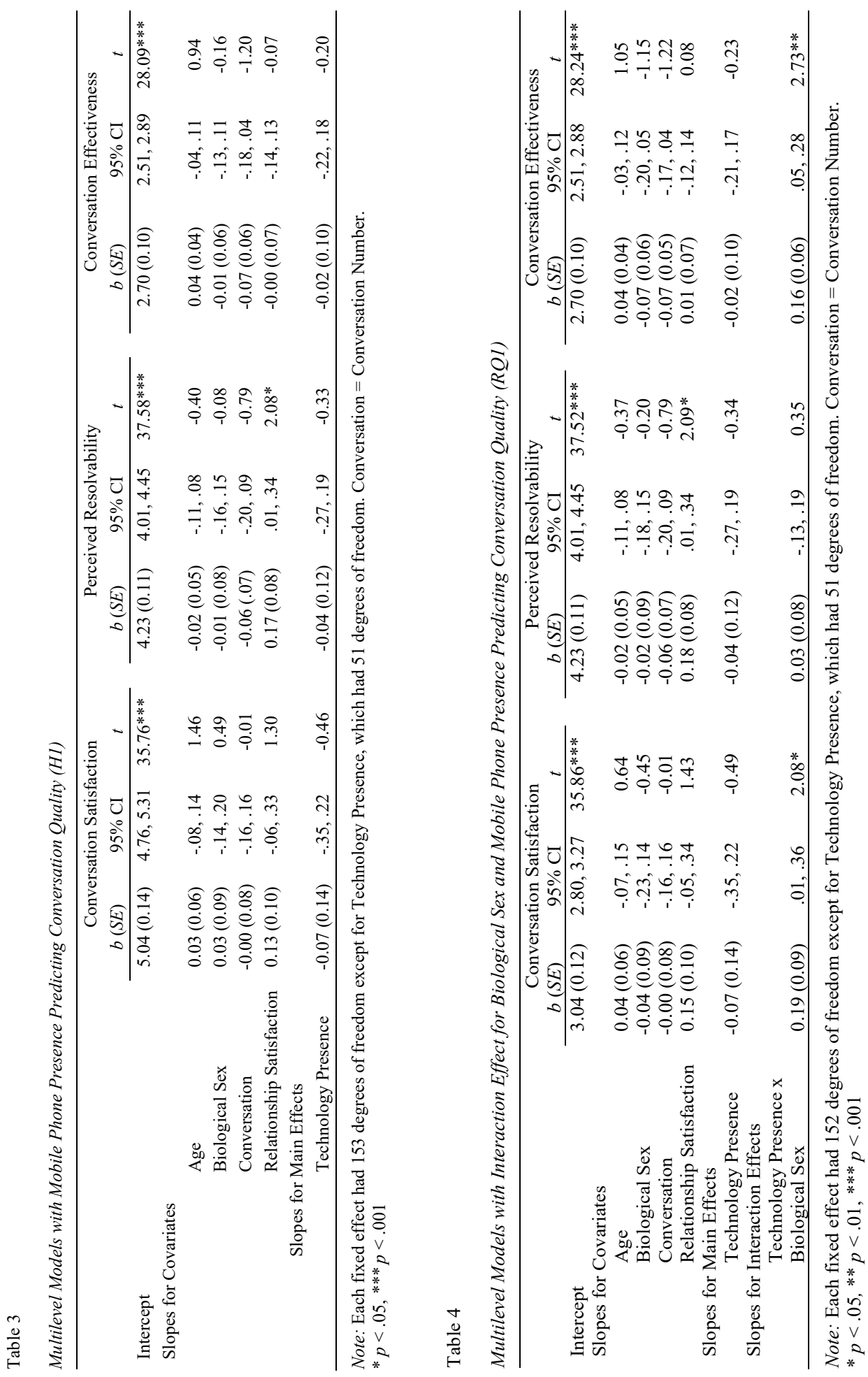


negative slope for females, $b=-0.19, t(152)=-1.64, p=0.10$. Conversely, the slope for males was positive, $b=0.14, t(152)=1.26, p=0.21$.

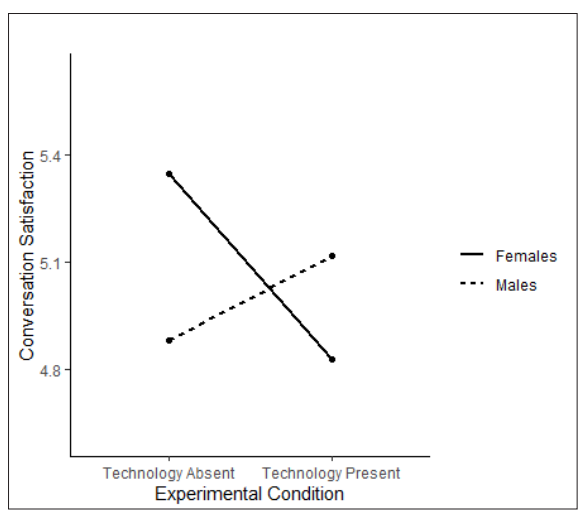

Figure 1. Simple slopes for 2-way interaction between participant sex and experimental condition predicting conversation satisfaction.

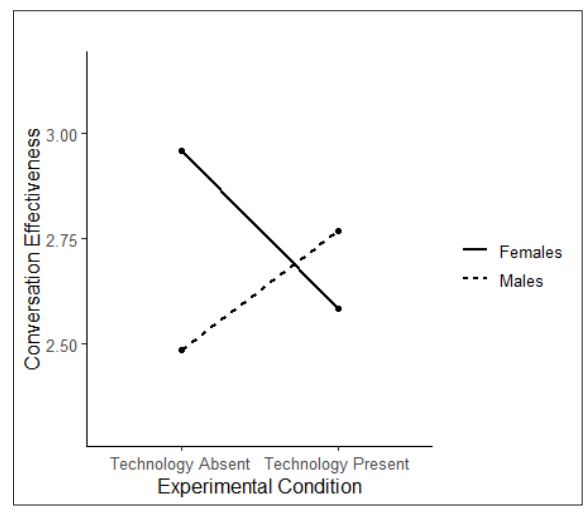

Figure 2. Simple slopes for 2-way interaction between participant sex and experimental condition predicting conversation effectiveness.

Smartphone presence, communication behaviors, and conversation quality. Hypothesis 2 predicted that positive communication would be positively associated with conversation quality and that negative communication would be negatively associated with conversation quality (even in the presence of technology). The presence of technology and either positive communication or negative communication behaviors were entered in three models for conversation quality (see Table 5 and Table 6). Technology presence did not significantly predict conversation quality when included in models with communication behaviors. However, the index of positive communication behaviors was associated with greater conversation satisfaction $\left(b=0.48, p<.001, R^{2}=.09,95 \% \mathrm{CI}[.03, .17]\right)$, perceived resolvability $\left(b=0.24, p=.019, R^{2}=.03,95 \%\right.$ CI $\left.[.01, .09]\right)$, and conversation effectiveness ( $b=$ $0.26, p=.002, R^{2}=.05,95 \%$ CI $\left.[.01, .13]\right)$. Negative communication behaviors were inversely associated with conversation satisfaction $\left(b=-0.38, p<.001, R^{2}=.06,95 \%\right.$ CI $[.01, .13])$, perceived resolvability $\left(b=-0.20, p=.012, R^{2}=.05,95 \%\right.$ CI $\left.[.01, .10]\right)$, and conversation effectiveness $\left(b=-0.16, p=.013, R^{2}=.04,95 \%\right.$ CI $\left.[.02, .15]\right)$.

Finally, RQ2 queried whether the presence of communication technology would moderate the associations between the communication behaviors and the ratings of the quality of their relational conflicts. The results for RQ2 showed no significant interactions between positive communication and the presence of technology nor negative communication and technology in the models for conversation quality. See Table 7 and Table 8 for model summaries.

\section{Discussion}

The current study was designed to study both the presence of smartphones and the nature of the face-to-face communication within the same study. This approach is a departure from most past work, which typically preferences one or the 

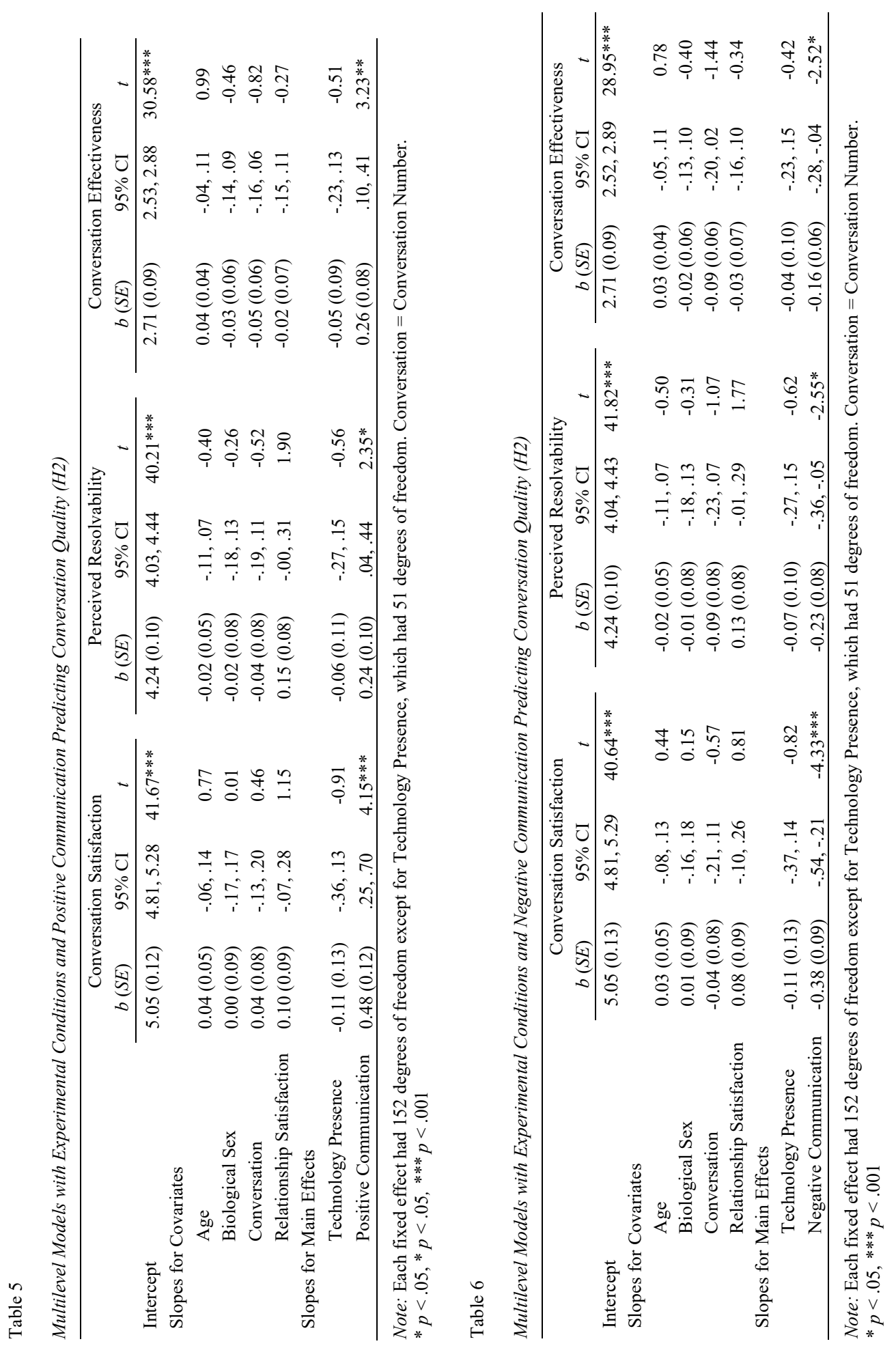


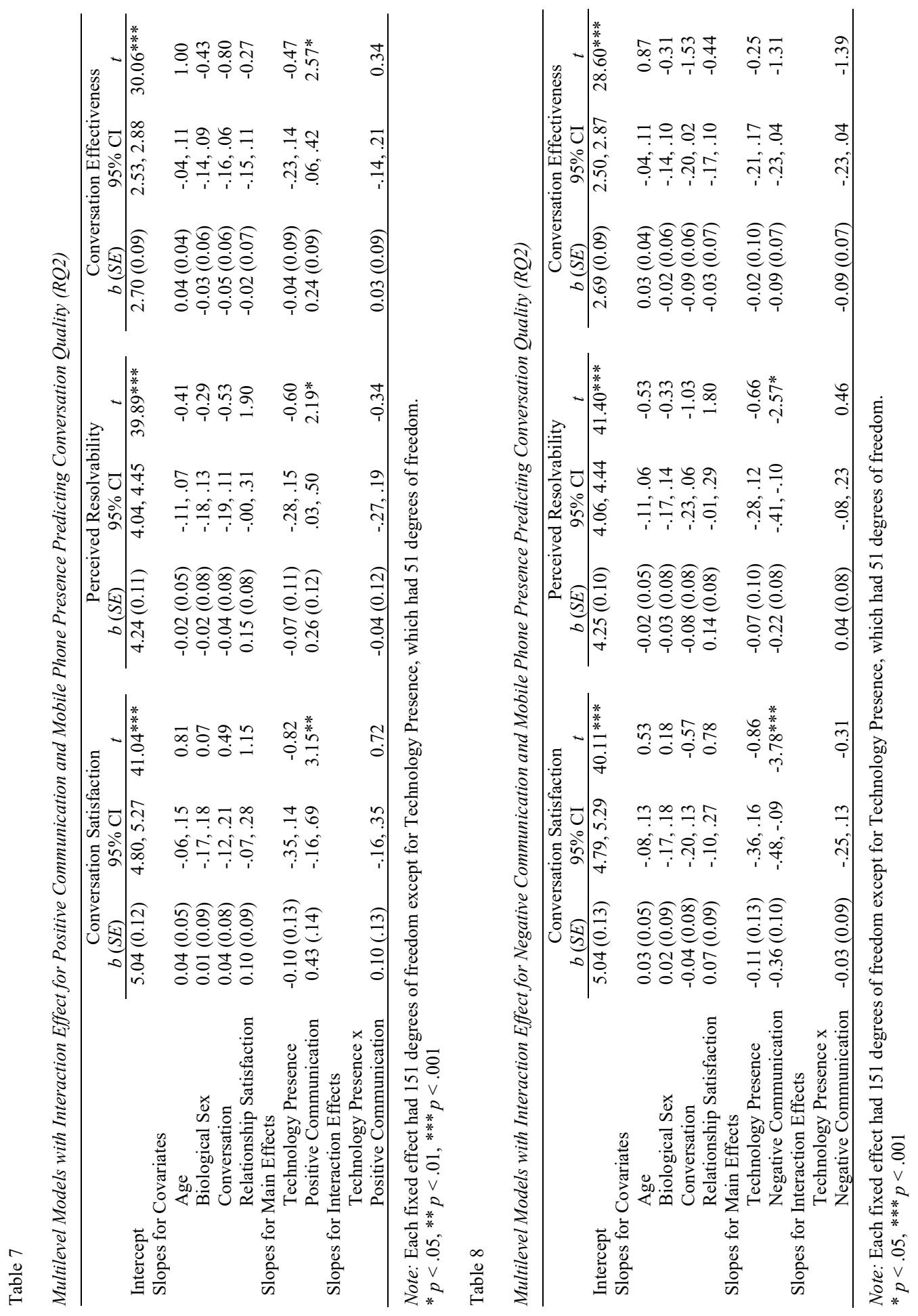


other. Based on the precepts of the communication interdependence model, we argue that by studying both technologies and face-to-face processes together, one can glean more information about relational communication than is possible by looking at either alone.

Overall, our results suggested that the communication behaviors previously known to shape the course of relational conflicts are much more strongly related to the outcomes of relational conflicts than is the mere presence of mobile technologies. Specifically, our results did not provide any evidence that the presence of mobile phones impacted conversation quality overall (H1), but biological sex moderated the impact of the presence of mobile technology such that the association between the presence of technology and satisfaction was more negative for women than it was for men (RQ1). The most salient findings were related to conflict behaviors. The amount of positive communication predicted greater conversation quality across each outcome variable, whereas the amount of negative communication predicted lower conversation quality $(\mathrm{H} 2)$. There was no evidence that the presence of technology moderated the associations of positive or negative communication with conversation quality (RQ2).

This study is the first we are aware of to examine the impact of the presence of mobile phones on interpersonal interaction that also examines the nature of the interpersonal communication behaviors. The findings provide evidence that the established understanding of how relational conflict functions still applies when smartphones are present, even though many of the findings in the conflict literature predate widespread use of mobile technologies. Indeed, the findings pertaining to behaviors during the conflict were very consistent with what would be expected based on past literature (e.g., Canary \& Sillars, 2013; Roloff \& Wright, 2013).

There also was no evidence that outcomes usually associated with positive and negative conversational behaviors were moderated by the presence of mobile devices. This is important because claims about how mobile technologies are fundamentally transforming relationships have become common (e.g., Passy, 2019; Sbarra et al., 2019). Sbarra and colleagues even go so far as to suggest that "smartphones and their affordances" have created evolution-linked pulls away from the physically present to the technological networks, with "the potential to undermine immediate interpersonal interaction" (p. 596). The current results do not preclude the possibility that mobile technologies can interfere with conversations, but they demonstrate that the immediate interpersonal interaction still functions as it has. Our fundamental understanding of how to engage in conflict successfully is still applicable, even in contemporary circumstances with smartphones present. These findings are consistent with arguments that even as scholars focus on understanding the role of technology in relational interactions, they also need to consider the nature of interaction if they wish to understand conversational and relational outcomes (e.g., Ruppel, 2019). Although it is possible that our findings would not extend to other domains of relational communication, they do suggest that the substance of how people talk to each other is still an important determinant of the quality of interactions between relationship partners, regardless of whether their mobile phones are present or not.

Our findings with respect to the presence of mobile phones were more equivocal, with no overall main effect of technology but some evidence that the pres- 
ence of mobile phones may interact with sex differences. The overall null finding regarding the role of mobile phones on interaction quality is consistent with some recent work that has failed to find an effect of the presence of phones (Allred \& Crowley, 2016; Crowley et al., 2018), but the current findings are noteworthy because of the aforementioned reasons to expect that conflict is a context in which effects of mobile devices are particularly likely to be evident.

This investigation strengthens recent evidence suggesting that the effects of the presence of mobile phones are weaker than suggested by early work in this area. One plausible explanation is that findings from the initial studies conducted in this area may have observed a historical artifact when smartphones were new and novel and, therefore, particularly distracting for people (Crowley et al., 2018). Smartphone ownership has increased by 46\% since 2011 (Pew Research, 2019), and therefore people may have become more accustomed to their presence during everyday interactions.

It is also important to note that even as the evidence mounts that the presence of a smartphone by itself has a limited impact on relational communication, this should not be interpreted as a reason to reduce the focus on understanding the role of mobile technologies in relationships. The paradigm that examines the mere presence of technologies is a fairly simplistic view of how technologies matter to communication. Such studies do not, strictly speaking, espouse a technological determinism perspective because the presumed mechanisms for any effects involve the meanings and understandings people have of the devices, such as the notion that "people associate phones with wide-ranging social networks" (Przybylski \& Weinstein, 2013, p. 238). Still, the notion that the presence of a smartphone has a direct and enduring effect on conversation quality is analogous to technological determinism that is not tenable given the rich ways in which people use communication technologies in their relationships (e.g., Baym, 2015). Given the scholarly and popular press assumptions that the mere presence of mobile technologies has large effects, it has been important to test those assumptions, but our findings (and a growing body of work) suggest that if there is a general effect of the presence of technology itself, it might be too small to be detected on a consistent basis.

Although the overall effects of smartphones being present may be small, that does not mean they are unimportant. First, small overall effects can mask more prominent effects for some people. The current findings showed an indication of sex differences, such that the presence of technology might matter more to women for conversation satisfaction and conversation effectiveness. This finding suggests that even if the overall effects are not large, there still may be an important impact of technologies for some people (at least in some contexts). The sex differences in the current study are only one example of potential variations. Another potentially important variation may lie in how dyads and families negotiate rules for smartphone presence during conversations (Miller-Ott \& Kelly, 2016).

\section{Limitations and Future Directions}

The current study has a few noteworthy limitations. First, the participants were young adults in college. It is possible that the results of phone presence on conversation quality was not as strong for the current sample because younger 
adults "may be less sensitive to environmental cues" (Allred \& Crowley, 2016, p. 12). Although young adults ages 18-29 are the most likely to own a smartphone in the United States, midlife and older adults are seeing moderate growth in smartphone ownership (Anderson \& Perrin, 2017; Taylor \& Silver, 2019). Future research should consider examining whether parallel effects exist in samples other than young adults in college who may have always owned a smartphone (i.e., digital natives). Despite this limitation, young adults ages 18-49 report being more bothered by smartphone behavior than do adults age 50 and above (Vogels \& Anderson, 2020). This indicates that examining the effects of mobile technology for digital natives may be particularly relevant.

Second, our sample size has implications for the main and interaction effects detected in the results. The sample was not large enough to rule out small effects, which means that it would be inappropriate to interpret our findings as suggesting that there are no effects of smartphones being present. Likewise, this study had only modest power to detect medium sized effects. A larger sample would provide more definitive results. In addition, the detected biological sex interaction effects were small. However, despite the small sample size and power considerations, the size of the $R^{2}$ confidence intervals for the presence of technology indicates that we can rule out large effects. This limitation should be understood in context. The current study was consistent with norms for this type of research. For example, the Przybylski and Weinstein (2013) paper described studies with 37 and 34 dyads (compared to our 58 dyads), and it is more difficult to recruit bona fide relational dyads than matching zero history groups. The replication effort by Crowley et al. (2017) yielded effect sizes that are within the confidence intervals of the effects in the current study. Our sample was also large enough to evince strong evidence of the importance of communication behaviors.

Third, we used broad ratings of communication behaviors rather than specific behaviors or characteristics. These broad dimensions certainly obscure meaningful variations within the larger categories of positivity and negativity (Sillars, 1986). It is likely that taking such a broad approach underestimates the complete association between conflict management behaviors and the conversational outcomes. Thus, even though this study demonstrated that traditional conflict management behaviors are more closely related to outcomes than is the presence of mobile phones, this study may have underestimated the relative importance of communication behaviors during conflicts. Hence, future investigations of technology presence during face-to-face interactions should take extra care to explore the myriad of verbal and nonverbal communication behaviors that impact conversation quality.

Fourth, the current study should be augmented with more naturalistic studies because "relational communication is situated and only fully understandable when examined in context" (Sillars \& Vangelisti, 2018, p. 252). Like all laboratory studies of relational conflict, it is possible that the design of the study influenced participants' conflict behaviors. In particular, studies that ask couples to discuss a topic often diminish the prevalence of conflict avoidance (Kluwer, Heesink, \& Van de Vliert, 1997; Roberts, 2000). Additionally, although the current design examined the presence of smartphones, the results cannot be extrapolated to how people use smartphones in everyday circumstances. For example, some college 
students report using their smartphones to avoid conflicts in their everyday interactions, such as by using their phones to avoid looking at their partner (Caughlin et al., 2017). The use of a phone during an interaction may also be associated with decreased conversation quality, especially if the use is perceived as phubbing (Roberts \& David, 2016). Likewise, phone use evokes more negative reactions than does the presence of the smartphone by itself (Caplan \& Courtright, 2019). Smartphone use during conflict interactions may also undermine conversation quality more than the presence of the devices alone (Roaché, 2019). The current design did not allow us to examine whether the way people use their smartphones affects conflict management and the outcomes of conflict, but this is clearly an important issue for future research.

As scholars begin to focus more on the ways smartphones are used than whether they are merely present, the communication interdependence perspective used in the current study would suggest that the impact of the technologies may depend on how relational partners use them as part of their larger pattern of communicating. The communication interdependence perspective also provides a theoretical basis for conceptualizing the connections between smartphone use and other relational communication behaviors; specifically, it is "important to recognize the potential for the different modes of interaction to function well together or to interfere with each other" (Caughlin \& Sharabi, 2013, p. 887). As Sharabi and Dorrance Hall (2020) found, dating partners sometimes use mobile technologies in destructive ways (e.g., saving a text as evidence to try to win an anticipated conflict), but they can also use them in constructive ways to facilitate togetherness (e.g., talking with each other about something interesting on one's phone). We are only beginning to understand the complexities of how mobile technologies are utilized in relationships and to what effects. A true understanding of mobile technologies and relational communication will require us to have richer descriptions of the ways communication technologies can interconnect with face-to-face discourse. Additionally, future work should consider how the larger relational context that may shape the meaning and effects of using technologies; for instance, looking at one's phone for five seconds while talking to a partner in an affectionate relationship with few conflicts may seem unremarkable, but the exact same behavior in a relationship with salient unresolved conflicts may be viewed as phubbing.

\section{Conclusion}

This study contributes to our understanding of the impact that technology has on face-to-face interactions. The findings strongly suggest that mobile phones do not fundamentally alter the importance of interpersonal conflict behaviors - what we know about constructive conflict appears to apply to a world in which smartphones are nearly always present. Additionally, despite being a context in which the presence of smartphones could be particularly problematic, the results showed no evidence that the presence of mobile phones had an impact on serial argument conversation quality. The sex differences in the current study, however, suggest that some individuals may be more reactive to the presence of technology than others; thus, further examination of this possibility is warranted. Notwithstanding these potential avenues for future research, the most prominent findings of the 
current study imply that the established literature on what breeds dissatisfaction in conflict interactions continues to be important, suggesting that the fundamental principles of constructive conflict endure, even as communication technologies become more widespread and important.

\section{Acknowledgements}

The authors would like to thank Bryan Abendschein, Chelsea Butkowski, Marielle Dickens, Tanya D'Silva, Carolyn Huizar, Jose Izaguirre, Jordyn Kass, Rachel Kimnach, Jiayi Liu, Sahana Moodabagil, Katie Quagliano, Laura Saldivar, Erin Wehrman, and Lillie Williamson for their assistance with this project.

\section{Funding: None}

Conflict of Interests: None

\section{References}

Aiken, L. S., \& West, S. G. (1991). Multiple regression: Testing and interpreting interactions. Sage.

Allred, R. J., \& Crowley, J. P. (2016). The "mere presence" hypothesis: Investigating the nonverbal effects of cell-phone presence on conversation satisfaction. Communication Studies, 68(1), 22-36. https://doi.org/10.1080/10510974.2016.124 1292

Anderson, M.., \& Perrin, A. (2017, May 17). Tech adoption climbs among older adults. Retrieved from https://www.pewinternet.org/2017/05/17/tech-adoption-climbs-among-older-adults/

Baym, N. K. (2015). Personal connections in the digital age. Polity Press.

Caplan, S. E. (2018). The changing face of problematic Internet use: An interpersonal approach. Peter Lang.

Caplan, S. E., \& Courtright, J. A. (2019, November). The effects of mobile device use and presence on in-person conversations. Paper presented at the convention of the National Communication Association, Baltimore, MD.

Caughlin, J. P., Basinger, E. D., \& Sharabi, L. L. (2017). The connections between communication technologies and relational conflict: A multiple goals and communication interdependence perspective. In J. A. Samp (Ed.), Communicating interpersonal conflict in close relationships: Contexts, challenges and opportunities (pp. 57-72). Routledge.

Caughlin, J. P., \& Sharabi, L. L. (2013). A communicative interdependence perspective of close relationships: The connections between mediated and unmediated interactions matter. Journal of Communication, 63(5), 873-893. https://doi. org/10.1111/jcom.12046

Caughlin, J. P., Vangelisti, A. L., \& Mikucki-Enyart, S. L. (2013). Conflict in dating and marital relationships. In J. G. Oetzel \& S. Ting-Toomey (Eds.), The Sage handbook of conflict communication: Integrating theory, research, and practice (pp. 161-186). Sage. 
Cohen, J. (1992). A power primer. Quantitative Methods in Psychology, 112(1), 155199. https://doi.org/10.1037/0033-2909.112.1.155

Crowley, J. P., Allred, R. J., Follon, J., \& Volkmer, C. (2018). Replication of the mere presence hypothesis: The effects of cell phones on face-to-face conversations. Communication Studies, 69(3), 283-293. https://doi.org/10.1080/10510974.2018.1 467941

Cupach, W. R. (2015). Communication competence in the management of conflict. In A. F. Hannawa \& B. H. Spitzberg (Eds.), Handbook of communication science (Vol. 22, pp. 341-366). De Gruyter Mouton.

Davies, J. J., Bird, B., Chaffin, C., Eldridge, J., Hoover, A., Law, D., Munyan, J., \& Shurtliff, K. (2012). Habitual, unregulated media use and marital satisfaction in recently married LDS couples, Western Journal of Communication, 76(1), 6585. http://dx.doi.org/10.1080/10570314.2012.637541

Dwyer, R., Kushlev, K., \& Dunn, E. (2018). Smartphone use undermines enjoyment of face-to-face social interactions. Journal of Experimental Social Psycholo$g y, 78,233-239$. https://doi.org/10.1016/j.jesp.2017.10.007

Field, A., Miles, J., \& Field, Z. (2012). Discovering statistics using R. Sage.

Fincham, F. D., Rogge, R., \& Beach, S. R. H. (2018). Relationship satisfaction. In A. L. Vangelisti \& D. Perlman (Eds.), The Cambridge handbook of personal relationships (2nd. ed., pp. 422-436). Cambridge University Press.

Fletcher, G. J. O., Simpson, J. A., \& Thomas, G. (2000). The measurement of perceived relationship quality components: A confirmatory factor analytic approach. Personality and Social Psychology Bulletin, 26(3), 340-354. https://doi. org/10.1177/0146167200265007

Forgays, D. K., Hyman, I., \& Schreiber, J. (2014). Texting everywhere for everything: Gender and age differences in cell phone etiquette and use. Computers in Human Behavior, 31, 314-321. https://dx.doi.org/10.1016/j.chb.2013.10.053

Hecht, M.L.(1978). Toward a conceptualization of communication satisfaction. Quarterly Journal of Speech, 64(1), 47-62. https://doi.org/10.1080/00335637809383411

High, A. (2019). Theorizing a more complete picture: Integrating interpersonal communication with computer-mediated communication. Human Communication \& Technology, 1(1), 22-26. https://doi.org/10.17161/hct.v1i1.11977

Johnson, K. L., \& Roloff, M. E. (1998). Serial arguing and relational quality: Determinants and consequences of perceived resolvability. Communication Research, 25(3), 327-343. https://doi.org/10.1177/009365098025003004

Kenny, D. A., Kashy, D. A., \& Cook, W. L. (2006). Dyadic data analysis. Guilford Press.

Kluwer, E. S., Heesink, J. A. M., \& Van de Vliert, E. (1997). The marital dynamics of conflict over the division of labor. Journal of Marriage and the Family, 59(3), 635-653. https://doi.org/10.2307/353951

Koo, T. K., \& Li, M. Y. (2016). A guideline of selecting and reporting intraclass correlation coefficients for reliability research. Journal of Chiropractic Medicine, 15(2), 155-163. https://doi.org/10.1016/j.jcm.2016.02.012

Kreft, I., \& de Leeuw, J. (1998). Introducing multilevel modeling. Sage.

LaHuis, D. M., Hartman, M. J., Hakoyama, S., \& Clark, P. C. (2014). Explained variance measures for multilevel models. Organizational Research Methods, 17(4), 433-451. https://doi.org/10.1177/1094428114541701 
Lorah, J. (2018). Effect size measures for multilevel models: Definition, interpretation, and TIMSS example. Large-Scale Assessments in Education, 6(1), 1-11. https://doi.org/10.1186/s40536-018-0061-2

McDaniel, B. T., \& Coyne, S. M. (2016). "Technoference": The interference of technology in couple relationships and implications for women's personal and relational well-being. Psychology of Popular Media Culture, 5(1), 85-98. https:// doi.org10.1037/ppm0000065

Miller-Ott, A. E., \& Kelly, L. (2016). Competing discourses and meaning making in talk about romantic partners' cell-phone contact with non-present others. Communication Monographs, 67(1), 58-76. https://doi.org/10.1080/10510974.201 5.1088876

Misra, S., Cheng, L., Genevie, J., \& Yuan, M. (2016). The iPhone effect: The quality of in-person social interactions in the presence of mobile devices. Environment and Behavior, 48(2), 275-298. https://doi.org/10.1177/0013916514539755

Murayama, K., Usami, S., \& Sakaki, M. (2020, May 11). A simple and easy method for power analysis in mixed-effects modelling with nested data: Just a $t$ value often suffices. https://doi.org/10.31219/osf.io/6cer3

Nakagawa, S., \& Schielzeth, H. (2013). A general and simple method for obtaining $\mathrm{R}^{2}$ from generalized linear mixed-effects models. Methods in Ecology and Evolution, 4(2), 133-142. https://doi.org/10.1111/j.2041-210x.2012.00261.x

Papp, L. M., Kouros, C. D., \& Cummings, E. M. (2009). Demand-withdraw patterns in marital conflict in the home. Personal Relationships, 16(2), 285-300. https:// doi.org/10.1111/j.1475-6811.2009.01223.x

Parks, M. R. (2017). Embracing the challenges and opportunities of mixed-media relationships. Human Communication Research, 43(4), 505-517. https://doi. org/10.1111/hcre.12125

Passy, J. (2019). Your smartphone is killing your relationship - and evolution is to blame. Retrieved from https://www.marketwatch.com/story/your-smartphone-iskilling-your-relationship-and-evolution-is-to-blame-2019-02-13

Pew Research Center (2019, June 12). Mobile fact sheet. Retrieved from http://www. pewinternet.org/fact-sheet/mobile/.

Pinheiro, J., Bates, D., DebRoy, S., Sarkar, D., \& R Core Team (2018). nlme: Linear and nonlinear mixed effects models. $\mathrm{R}$ package version 3.1-131.1. https:// CRAN.R-project.org/package $=$ nlme

Przybylski, A. K., \& Weinstein, N. (2013). Can you connect with me now? How the presence of mobile communication technology influences face-to-face conversation quality. Journal of Social and Personal Relationships, 30(3), 237-246. https:// doi.org/10.1177/0265407512453827

Pusateri, K. B., Roaché, D. J., \& Wang, N. (2015). The role of communication technologies in serial arguments: A communicative interdependence perspective. Argumentation \& Advocacy, 52(1), 44-60. https://doi.org/10.1080/00028533.2015 .11821860

Rainie, L., \& Zickuhr, K. (2015, August 26). Americans' views on mobile etiquette. Pew Research Center. Retrieved from http://www.pewinternet.org/2015/08/26/ americans-views-on-mobile-etiquette/

Roaché, D. J. (2019, November). Can you just leave your phone out of it? An examination of the impact of co-present smartphone use on relational conflict. Paper present- 
ed at the convention of the National Communication Association, Baltimore, MD.

Roberts, J. A., and David, M. E. (2016). My life has become a major distraction from my cell phone: Partner phubbing and relationship satisfaction among romantic partners. Computers in Human Behavior, 54, 134-141. https://doi. org/10.1016/j.chb.2015.07.058

Roberts, L. J. (2000). Fire and ice in marital communication: Hostile and distancing behaviors as predictors of marital distress. Journal of Marriage and the Family, 62(3), 693-707. https://doi.org/10.1111/j.1741-3737.2000.00693.x

Roloff, M. E., \& Chiles, B. W. (2011). Interpersonal conflict: Recent trends. In M.L. Knapp \& J.A Daly (Eds.), The Sage handbook of interpersonal communication (4th ed., pp. 423-442). Sage.

Roloff, M. E., \& Wright, C. N. (2013). Social cognition and conflict. In J. G. Oetzel \& S. Ting-Toomey (Eds.), The Sage handbook of conflict communication: Integrating theory, research, and practice (pp. 133-160). Sage.

Ruppel, E. K. (2019). Putting (human) communication at the center of technology studies. Human Communication $\mathcal{E}$ Technology, 1(1), 9-12. https://doi. org/10.17161/hct.v1i1.12059

Sbarra, D. A., Briskin, J. L., \& Slatcher, R. B. (2019). Smartphones and close relationships: The case for an evolutionary mismatch. Perspectives on Psychological Science, 14(4), 596-618. https://doi.org/10.1177/1745691619826535

Scott, A. M., \& Caughlin, J. P. (2014). Enacted goal attention in family conversations about end-of-life health decisions. Communication Monographs, 81(3), 261284. https://doi.org/10.1080/03637751.2014.925568

Sharabi, L. L., \& Dorrance Hall, E. (2020). Conceptualizing and measuring communication interdependence: The technology and face-to-face integration scale. Manuscript submitted for publication.

Shrout, P. E., \& Fleiss, J. L. (1979). Intraclass correlations: Uses in assessing rater reliability. Psychological Bulletin, 86(2), 420-428. https://doi.org/10.1037/00332909.86.2.420

Sillars, A. L. (1986, April). Procedures for coding interpersonal conflict (revised) (Manual). Missoula: University of Montana, Department of Interpersonal Communication.

Sillars, A. L., \& Canary, D. J. (2013). Conflict and relational quality in families. In A. L. Vangelisti (Ed.), The Routledge handbook of family communication (2nd ed., pp. 338-357). Routledge.

Sillars, A. L., \& Vangelisti, A. L. (2018). Communication: Basic properties and their relevance to relationship research. In A. L. Vangelisti \& D. Perlman (Eds.), The Cambridge handbook of personal relationships (2nd. ed., pp. 243-255). Cambridge University Press.

Taylor, S. H., \& Bazarova, N. N. (2018). Revisiting media multiplexity: A longitudinal analysis of media use in romantic relationships. Journal of Communication, 68(6), 1104-1126. https://doi.org/10.1093/joc/jqy055

Taylor, K., \& Silver, L. (2019, February 5). Smartphone ownership is growing rapidly around the world, but not always equally. Pew Research Center. Retrieved from 
https://www.pewresearch.org/global/2019/02/05/smartphone-ownership-isgrowing-rapidly-around-the-world-but-not-always-equally/

Thornton, B., Faires, A., Robbins, M., \& Rollins, E. (2014). The mere presence of a cell phone may be distracting: Implications for attention and task performance. Social Psychology, 45(6), 479-488. https://doi.org/10.1027/1864-9335/a000216

Turkle, S. (2008). Always-on/always-on-you: The tethered self. In. J. E. Katz (Ed.), Handbook of mobile communication studies (pp. 121-137). MIT Press.

Vogels, E. A., \& Anderson, M. (2020, May 8). Dating and relationships in the digital age. Retrieved from https://www.pewresearch.org/internet/2020/05/08/dating-and-relationships-in-the-digital-age/

Wang, N., Roaché, D. J., \& Pusateri, K. B. (2019). Interconnection of multiple communication modes in long-distance dating relationships. Western Journal of Communication, 83(5), 600-623. https://doi.org/10.1080/10570314.2018.1552986

Ward, A. F., Duke, K., Gneezy, A., \& Bos, M. W. (2017). Brain drain: The mere presence of one's own smartphone reduces available cognitive capacity. Journal of the Association for Consumer Research, 2(2), 140-154. https://doi. org $/ 10.1086 / 691462$

Waldinger, R. J., \& Schulz, M. S. (2006). Linking hearts and minds in couple interactions: Intentions, attributions, and overriding sentiments. Journal of Family Psychology, 20(3), 494-504. https://doi.org/10.1037/0893-3200.20.3.494h

Whitton, S. W., James-Kangal, N., Rhoades, G. K., \& Markman, H. J. (2018). Understanding couple conflict. In A. L. Vangelisti \& D. Perlman (Eds.), The Cambridge handbook of personal relationships (2nd. ed., pp. 297-310). Cambridge University Press. 